Rubiliza DC. Onofre, MD

Department of Otorhinolaryngology

Head and Neck Surgery

East Avenue Medical Center

Correspondence: Rubiliza DC. Onofre, MD

Department of Otolaryngology Head and Neck Surgery 6th floor East Avenue Medical Center

East Avenue, Quezon City 1100

Philippines

Phone: (632) 9280611 loc 324

Fax: 435-6988

Email: Eamc_enthns@yahoo.com, yukito8211@yahoo.com Reprints will not be available from the author.

\section{Parapharyngeal Neurofibroma in a Pediatric Patient}

Primary tumors of the parapharyngeal area are rare and account for $0.5 \%$ of all head and neck tumors. ${ }^{1,2}$ Among these, $80 \%$ are benign while $20 \%$ are malignant. ${ }^{2}$ Next to schwannomas, neurofibromas are the second most commonly encountered primary tumor of nerve sheath origin in the parapharyngeal space but incidence and prevalence rates have not been documented among pediatric patients. ${ }^{3,4}$ Plexiform neurofibromas in particular pose a surgical challenge in pediatric patients. Careful preoperative planning, advanced surgical techniques and vigilant postoperative care result in minimal morbidity and resolution of tumor symptomatology. ${ }^{5}$

Although complete surgical resection is ideal for all (especially benign) parapharyngeal tumors, ${ }^{4}$ the dilemma of complete versus partial resection arises when massive size increases the possibility of neurological dysfunction and cosmetic deformity from damage to adjacent cranial nerves and sympathetic chain fibers. ${ }^{6}$

We present the management dilemma involving a neurofibroma of the parapharyngeal space in a pediatric patient.

\section{CASE REPORT}

A 9-year-old female consulted with a 5-year history of a right infraauricular mass with concomitant soft palatal swelling. A tonsillectomy had been previously performed in another institution, with note of the "mass extension at the right posterior tonsillar pillar bulging over the posterior pharyngeal wall." The histopathologic report was "chronic hypertrophic tonsil; plexiform neurofibroma," but the patient did not follow up and no further intervention took place until progressive enlargement of the infraauricular and soft palatal swelling prompted this consultation at our institution.

On examination, a firm non-tender $6 \times 5 \times 4 \mathrm{~cm}$ tumor in the right parotid region with medial displacement of the right lateral pharyngeal wall and soft palate were noted (Figure $1 A, B)$, together with an open bite deformity and whitish non-foul smelling discharge from the right external auditory canal. No cranial nerve deficits, café au late spots or lisch nodules were noted.

Contrast Computed Tomography (Figure 2) further revealed the mass extending anteriorly to the right post styloid space, superomedially to the inferior maxillary wall and posteriorly to the prevertebral space. The parotid was displaced laterally and the carotid artery and jugular vein, displaced posteriorly.

A wedge biopsy of the soft palate extension revealed neurofibroma.

\section{DISCUSSION}

Primary tumors of the parapharyngeal space are extremely rare. ${ }^{2}$ A search of HERDIN, PubMed and Cochrane using the keywords parapharyngeal, neurofibroma and pediatrics, yielded no locally-reported cases among children.

Neurofibromas ranked second among neuroblastic tumors that occur in the parapharyngeal space. ${ }^{2}$ Plexiform neurofibromas (PNs) are typically congenital with approximately 50\% occurring in the region of the head, neck, face and larynx. ${ }^{6}$ The growth pattern has not been fully understood, but they appear to grow in early childhood at variable rates with growth and plateau phases. Plexiform neurofibromas tend to be locally invasive and may result in cosmetic 


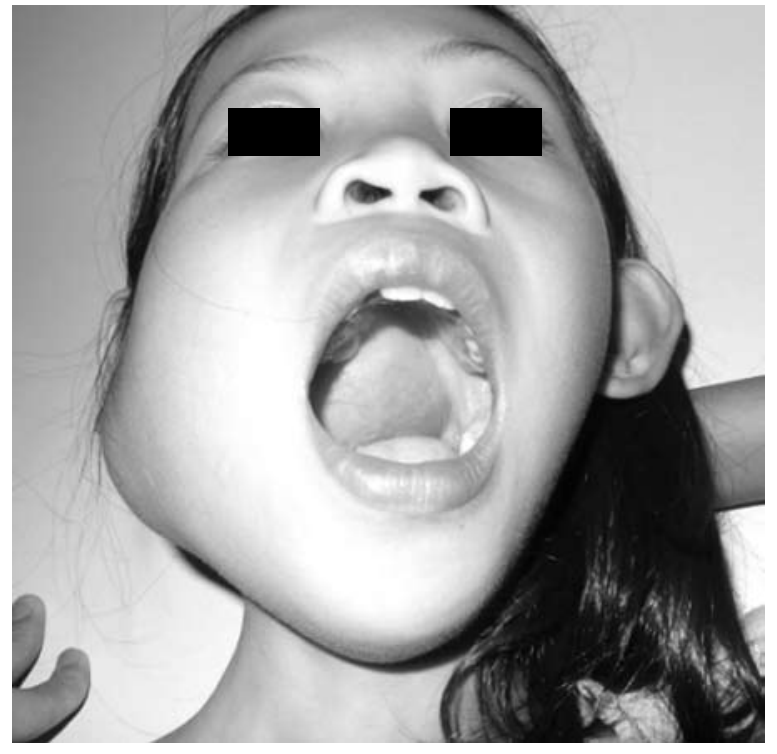

Figure 1. A Anterior view of right infra auricular mass measuring approximately $6 \times 5 \times 4 \mathrm{~cm}$

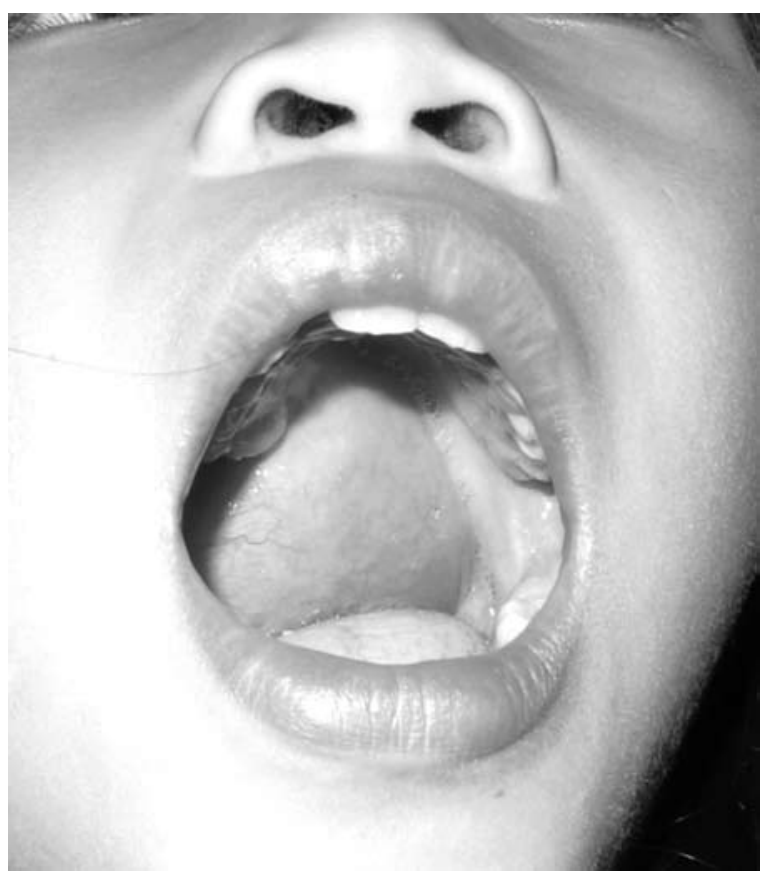

Figure 1 B. Close-up intraoral view showing palatal involvement. The right parapharyngeal wall was similarly involved.

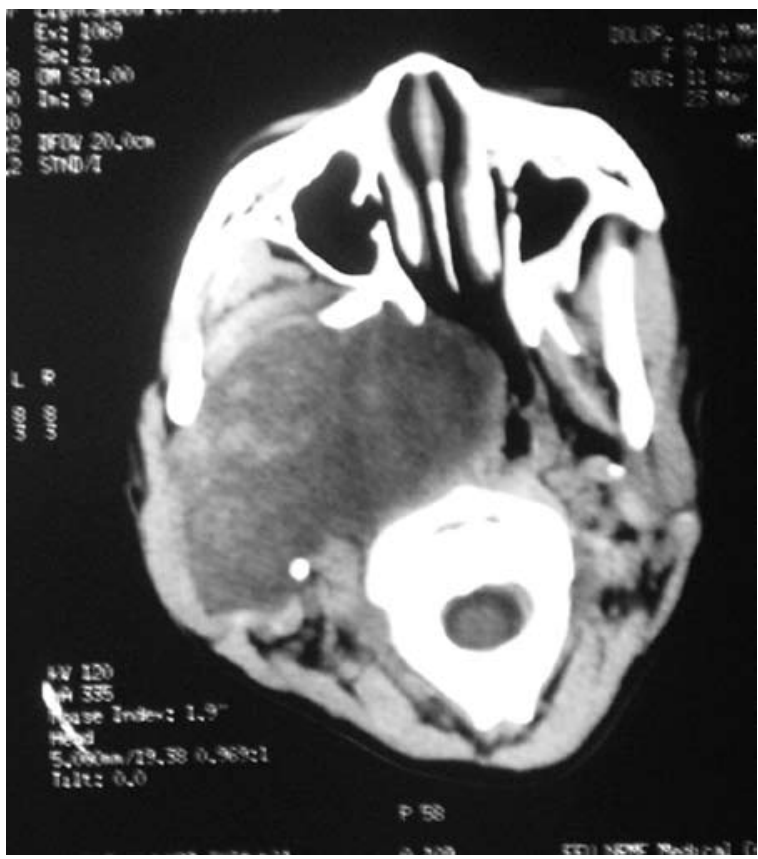

Figure 2. Contrast CT Scan, Axial view at level of the nasopharynx shows mass extending anteriorly to the posterior maxillary wall and pterygoid plate, posteriorly to the prevertebral space and medially to the contralateral nasopharynx, displacing the carotid artery and jugular vein posteriorly

deformities and functional deficits. Our patient has a noncutaneous plexiform neurofibroma but did not meet the criteria for the diagnosis of neurofibromatosis I.

The ideal treatment for parapharyngeal neurofibromas or schwanommas is surgery, ${ }_{1}^{5,78}$ aiming to completely remove tumor with preservation of surrounding nerves and vessels. ${ }^{5}$ Approaches which depend on tumor size and localization include the transparotid (commonly used for deep-lobe parotid and other pre styloid tumors); the transcervical (for post styloid tumors); and combinations of both. ${ }^{7,8,9}$ A mandibulotomy may be added to increase exposure but poses risk of injury to the inferior alveolar nerve while providing access to the parapharyngeal space.

The goal of complete excision without damaging the vagus, trigeminal, brachial plexus and sympathetic nerves or violating the carotid artery and jugular vein that may result in such complications as facial nerve weakness (trigeminal nerve), Horner's syndrome (cervical sympathetic nerve chain), median and ulnar nerve impairment (cervical and brachial nerve plexus), excessive bleeding (carotid artery and jugular vein) is easier said than done. ${ }^{5}$ Further complications of a possible mandibulotomy include inferior alveolar nerve anesthesia, loss of dentition, malocclusion, malunion or nonunion and possible need for a tracheotomy.

These complications will greatly affect the quality of life and functions of the patient in exchange for removal of a benign tumor that is presently not causing any such problems (except for otitis media 


\section{FEATURED GRAND ROUNDS}

possibly related to Eustachian tube compression). On the other hand, tumor enlargement may eventually cause greater problems if surgery is not performed now. If the tumor were small, resection would not have been as much a problem. ${ }^{8}$

Chemotherapy has been considered for such large tumors where surgical complications are likely based on findings that desmoid tumors are similar to plexiform neurfibromas. Current trials with such agents as combination methotrexate and vinblastine focus on slowing or stopping progression of existing disease. ${ }^{5,6}$ Farnesyl transferase inhibitors are also being considered as alternative chemotherapeutic agents due to high levels of this enzyme found in these tumors. ${ }^{6}$ Other drugs being tested but with limited efficacy are interferon alfa with or without retinoic acid and thalidomide. ${ }^{10}$

A pilot study on the possible use of radiofequency in the treatment of head and neck neurofibromatosis done among five pediatric patients in early stages of the disease revealed partial diminution and stability of the mass. ${ }^{10}$ However, further studies are suggested to determine the optimal dose, frequency of sessions and possible complications.

We plan to attempt complete excision of the neurofibroma via a combined transparotid-transcervical approach with mandibulotomy and possible reconstruction using titanium plates and screws. Post operative mandibular and occlusion rehabilitation is also being considered as the orthognathic structures have already been deformed and malaligned by the mass.

The management of huge parapharyngeal tumors is complicated indeed. Important factors such as quality of life, age and emotional effects on the patient must be considered as equally important as extirpating the whole tumor itself. We must find the balance between helping remove the burden of an enlarging mass while preserving the good quality of life our patient deserves.

\section{ACKNOWLEDGEMENT}

The author would like to acknowledge the help, guidance and support of Consultant Doctors Angelo Monroy, Natividad Almazan and Felix Nolasco and Resident Doctors of the Department of Otorhinolaryngology Head and Neck Surgery of the East Avenue Medical Center.

\section{REFERENCES}

1. Doménech J, Monner Dieguez A, Cisa Lluís A, Marí Roig A, de Frías B, Jiménez R. Schwannoma parafaringeo: a propósito de un caso- Secondary functional veloplasty: a non-obstructive approach to valopharyngeal insufficiency. Rev Esp Cirug Oral y Maxilofac 2004;26(1):245-248

2. Hughes KV, Olsen KD, McCaffrey TV. Parapharyngeal space neoplasms, Head Neck 1995;17(15):124-130

3. Kuttesch JF, Ater JL. Brain tumors in childhood. In: Behrman RE, Kliegman RM, Jenson HB, eds. Nelson Textbook of Pediatrics. $17^{\text {th }}$ Edition. Pennsylvania: Elsevier; 2004, p. 1702-1710.

4. Luna-Ortiz K, Navarrete-Aleman JE, Granados-Garcia M, Herrera-Gomez A Primary parapharyngeal space tumors in a Mexican cancer center. Otolaryngol Head Neck Surg 2005;132(4):587-591.

5. Manolidis, S, Higuera S, Boyd V, Hollier LH. Single-stage total and near-total resection of massive pediatric head and neck neurofibromas. J Craniofac Surg. May 2006; 17(3); 506-510

6. Wise JB, Cryer JE, Belasco JB, Jacobs I, Elden E. Management of head and neck plexiform neurofibromas in pediatric patients with neurofibromatosis I. Arch Otolaryngol Head Neck Surg 2005;131:712-718.

7. Olsen KD. Tumors and surgery of the parapharyngeal space. Laryngoscope 1994; 104: 1-28.

8. Shahab R, Heliwell T, Jones AS. How we do it: A series of 114 primary pharyngeal space neoplasms. Clinical Otolaryngol 2005; 30: 364-367.

9. Diaz-Ordaz, EA. Surgery of the parapharyngeal space. In: Lore, JM. Medina, JE. An Atlas of Head and Neck Surgery. $4^{\text {th }}$ edition. Pennsylvania: Elsevier; 2005, p. 1365-1368

10. Baujat B, Krastinova-Lolov D, Blumen M, Baglin AC, Coquille F, Chabolle F. Craniofacial plexiform neurofibromatosis: A pilot study. Plast Reconstr Surg April 2006; 117: 1261-1268. 